\title{
FARMER'S LUNG: A REVIEW OF PRESENT KNOWLEDGE \\ BY
}

\author{
C. J. FULLER \\ From the Royal Devon and Exeter Hospital
}

(RECEIVED FOR PUBliCATION JULY 1, 1952)

\begin{abstract}
"Farmer's lung" was originally described in Britain by Campbell of Grange-over-Sands, Lancashire, in 1932. In 1936 and 1938 Fawcitt, who also lived in the North-West of England, published papers describing the condition, and came to the conclusion that it was due to an actual bronchomycosis, producing as evidence that he was able to culture moulds from the sputa of affected farmworkers. Duncan, in 1945, stated that he was not impressed by the bronchomycotic hypothesis, but Törnell, on the other hand, in 1946, published eight cases of "thresher's lung" which he believed to be due to moniliasis of the bronchial tract.

My interest in the condition was first aroused by Fawcitt's original paper in 1936, and I collected several undoubted cases over the next six years. Unfortunately all these records were lost in 1942 as a result of air raids, and it was not until the postwar years that it was possible to give further time and attention to the condition.
\end{abstract}

\section{Clinical Picture}

Farmer's lung may be divided into three phases ; (1) the acute isolated attack, (2) the subacute and more chronic condition which shows a spontaneous tendency to recover, and (3) the chronic and irreversible phase where secondary lung changes such as emphysema and fibrosis have occurred as a result of repeated exposure over a period of years.

The clinical and radiological features of my cases appear to be identical with those described by others, notably Törnell, under the term "thresher's lung," and there seems to be no reasonable doubt that the two conditions are one and the same.

PHASE 1.-The acute attack is characteristic, being rapid in onset and accompanied by a rigor with rise of temperature on the evening of the day of exposure. This temperature does not generally rise above 100 to $101^{\circ} \mathrm{F}$. and lasts for only two or three days. It is accompanied by an irritating cough and some mucopurulent sputum which in severe cases is freely blood-stained. A few rhonchi and crepitations may be heard in the chest but no signs of consolidation. Frontal headache of a peculiarly persistent type, lassitude, and marked anorexia are also usually present, the anorexia and headache persisting several days after all chest symptoms have gone. A radiograph of the chest may show nothing abnormal after a single exposure, and the patient is able to return to work after a few days. Many of these cases are not recognized, and, even if the patient goes to his doctor, he is frequently thought to have a "feverish cold" and seen on only one occasion.

Example.-G.S., a farm-worker aged 31, with four other men had, on the day he was taken ill, been threshing a rick of mixed oats, barley, and beans which was unusually dusty.

He stopped work at 5 p.m., and two hours later began to feel tired, shivery, and ached all over. He took aspirin and the next day developed a cough with blood-stained sputum. He said that his chest felt tight and his breathing was quick. No temperature was recorded until three days after the onset, when it was $99.5^{\circ} \mathrm{F}$. He was first seen by me one week after the onset. He then complained of marked loss of appetite, but said that his cough had almost gone. There was no past history of asthma or hayfever, and the patient said that although he had been threshing for several years he had never before been affected in this way. The other members of this threshing team were all affected in varying degrees by this particular rick, but none so badly as this man.

Examination of the chest showed no abnormal physical signs. There was no cyanosis or finger clubbing. The throat was normal. Blood pressure was $120 / 72 \mathrm{~mm}$. $\mathrm{Hg}$, and the cardiovascular system was normal. A radiograph of the chest was normal. The blood count was normal. A Mantoux test with 1:1,000 O.T. was negative. The sputum showed normal bacterial flora only: there was no excess of eosinophils.

The patient was away from work for three weeks.

Phase 2.-The second phase is much more incapacitating and therefore forces the patient to seek medical advice. It is at this stage of the disease that the patient is usually seen in the hospital out-patient department and shows the 
fully developed syndrome. Inquiry will usually elicit the fact that he has, during the previous two or three months, been feeding a mouldy rick of hay to his cattle, or, alternatively, has been threshing several mouldy ricks of corn in succession.

The symptoms are of increasing breathlessness with a short, dry cough. The amount of sputum is small and it is mucopurulent. The patients will also admit to feeling shivery at night after exposure to the hay dust, as has already been described in the acute type.

Examination of such a patient will show him to be cyanosed and sufficiently breathless to show some distress when asked to take off his clothes to be examined. The haemoglobin content of the blood is usually raised, reaching $134 \%$ in one case.

The chest is somewhat emphysematous, but there are no expiratory sibilant rhonchi as is the case with bronchial spasm from asthma, the only added sounds being a varying number of crepitations heard more particularly over the lower lobes. The radiographs are characteristic, and it is interesting that a longer exposure than usual is necessary to get a good film, owing to the increased lung density. The picture is that of fine alveolar mottling, particularly noticeable in the middle and lower zones, associated with some compensatory emphysema.

This condition, or what has been termed Phase 2 , will clear up spontaneously if the worker is removed from contact with the dusty hay or straw. $\mathrm{He}$ will be quite free from symptoms in four to eight weeks, but residual radiographic changes usually persist for three or four months. The condition will, however, recur if the worker continues to use that particular rick of hay when he has recovered from his initial attack. Two examples of this relapse have been noted in farmers who either could not afford to discard a considerable amount of hay or thought that the doctor was being unduly fussy.

Example.-T. H. R., a farmer aged 51, stated that seven weeks previously he had had an attack of "influenza" for which he had stayed in bed for three days. When he got up he found that he was short of breath and unable to walk uphill. No oedema of the ankles had been noted by his general practitioner. On questioning him he admitted to having started to use a rick of mouldy hay for his cows about 10 days before his illness. He had not yet gone back to work and said that he was feeling much better, with very little cough or sputum.

There was no history of asthma, hay-fever, or eczema, either in the patient or his family.

Examination showed him to be high coloured; his weight was $168 \mathrm{lb}$. (76 kg.). There was no finger clubbing. The only abnormality in the lungs was numerous crepitations over both lower lobes at the back. The cardiovascular system was normal and the blood pressure $120 / 75 \mathrm{~mm}$. Hg. A radiograph showed extensive mottling of both lung fields in the middle and lower zones. Haemoglobin was $93^{\prime \prime}$, , and leucocytes were 7,400 per c.mm. (neutrophils $78.0 \%$. eosinophils $0.5 \%$, lymphocytes $21.0 \%$, monocytes $0.5 \%$ ). A Mantoux test with $1: 1.000$ O.T. was negative. Blood sent to the Virus Reference Laboratory showed no significant titre of antibodies to $H$. influenzae A and B. Q fever. psittacosis, and Streptococcus M.G.

Sputa showed Streptococcus viridans, Staphylococcus albus, and coliform bacilli on culture. No $M$. tuberculosis was seen in Z-N films. Culture on Sabouraud's medium showed a light growth of Candida albicans.

Radiographs taken a month later showed a marked improvement in both lungs.

A month later the patient volunteered that on one occasion since he had been seen originally he had had to use the mouldy hay himself and on that night he had felt sick and shivery.

It is notable that this case was originally thought to be one of influenza. and it was not until persistent exertional dyspnoea cast doubts on the diagnosis that the possibility of farmer's lung was considered. The negative results from the Virus Reference Laboratory left little doubt that the original diagnosis was inaccurate.

Phase 3.-Proved cases of the third, or chronic, phase are much less common. In the first place it is extremely difficult to obtain a clear history of the condition over a period of many years, unless by personal observation, and, secondly, scattered fibrosis with emphysema and bronchiectasis is a relatively common syndrome with many causes quite unassociated with farmer's lung, and the mere presence of mould spores in a sputum from a patient with diffuse pulmonary fibrosis is valueless.

This third phase differs in no way from the $\frac{T}{O}$ scattered pulmonary fibrosis with its attendant changes which is the end-result in other nonsilicotic, dust-borne diseases, and may be found in cotton spinners, bagasse workers, and maltsters; when it is reached the condition is irreversible and causes permanent incapacity.

Example.-K. J., a farm-worker aged 43, stated that he had had a cough for the past 20 years. He dated the onset of his symptoms to threshing a rick of mouldy straw, and stated that after doing so he developed feverishness, cough, and shortness of breath. Since then he had been prone to exertional dyspnoea, and if he came into contact with either mouldy straw or hay he would suffer a recurrence of his symptoms. Fresh hay, on the other hand, caused him no inconvenience. No history of asthma 
or hay-fever had been noted, but his breathlessness had slowly increased.

Examination showed him to be thin and asthenic. Chest movements were poor, the trachea displaced a little to the right. He had no clubbing or cyanosis. There were signs of fibrosis in the upper zones of both lungs with emphysema at the bases.

Repeated sputum examinations failed to show M. tuberculosis. A Mantoux test (1 in 1,000 O.T.) was negative. The vital capacity was $2,080 \mathrm{ml}$. Radiographs showed fibrosis of the upper zones of both lungs, bilteral emphysema, no evidence of hiatus hernia, and a normal stomach and duodenum.

\section{INCIDENCE IN DEVONSHIRE}

In the past eight years a total of 32 cases, all males, have been collected. Of these, five were examples of the short acute attack, 24 of the subacute phase, and three of chronic pulmonary damage. The relative numbers occurring in each group are not significant, for a Devon farmer avoids hospital if he can, and if he is suffering only from a mild acute attack of farmer's lung he probably does not seek medical advice.

The length of history varied between a few days and 20 years, and most cases occurred in the third and fourth decades. There - was no history of allergy in the sense of asthma, hay-fever, or eczema, either in the individual or in his family. The sputa were mucopurulent ; cultures revealed a typical mixed catarrhal bacterial flora, and microscopy showed on only one occasion a large number of eosinophils $(30 \%)$, while in the rest polymorphs have predominated. Curschmann's spirals and Charcot-Leyden crystals were notable by their absence.

As is the case in the Lake District and NorthWest of England, the rainfall in the South-West of England is high, and it frequently happens that the summer weather is broken by rain storms of greater or less frequency during both the hay harvest in late June and the corn harvest in August and September.

If a farmer, through the threat of wet weather, "carries" his hay before the sap has been dried out of it by the action of the wind and sun, the rick so formed will heat due to fermentation to such an extent that it may actually burst into flames and char. A lesser degree of this process may occur, in which case the centre of the rick becomes brown and friable. Good hay, on the other hand, will have a sweet, tea-like smell but is not charred or disintegrated in any way, and it should show no mouldy pockets visible to the naked eye.

Mouldy or "fusty" hay is the result of overheating, not of fresh hay which has been put in a rick too soon, but of hay which has lain in the fields too long and during that time has been wetted by rain before being carried. In other words, it appears that the primary multiplication of mould spores occurs before the hay is put in the rick and that this is dependent on the presence of added moisture in the form of rain. In the case of corn crops such as oats, barley, and wheat similar weather conditions produce similar changes in the straw when placed in a rick. Furthermore, the grain itself, if owing to wet weather it cannot be carried, may germinate in the stook, and when subsequently threshed a great deal of it is spoiled and has become infected with moulds.

There are two principal classes of farm worker who may become exposed to high concentrations of hay and straw "dust"; first, those employed as dairymen and, secondly, those who work in threshing teams, moving about from one farm to another with the threshing machines.

In Devonshire many farms are small and the cowhouses dark and ill-ventilated. The custom in winter is that before the cows are brought in for the night the cowman shakes down a certain amount of hay from a loft, which is sited above the stalls, and if this hay is mouldy it is no exaggeration to say that he will be unable to see across the cowhouse owing to the cloud of dust floating in the air. After this is done the cows are brought in to be milked and stay there until the next morning. Thus the cowman will be exposed to a high concentration of mould spores and hay dust for about an hour each day, but only in the winter and early spring, approximately from December to April inclusive.

In the case of threshing teams the exposure occurs only when a rick of oats or barley or other grain is being threshed which has been harvested under poor conditions. The amount of dust in some cases is enormous, and over a period of eight to 10 hours the threshers get a large dose when dealing with a bad rick. The same team, however, may only be at risk for two or three consecutive days at a time, unless the weather during the previous harvest was exceptionally bad, resulting in a high proportion of poor quality straw. The increasing use of combine harvesters will, of course, reduce threshing from the rick as an aetiological factor.

\section{Aetiology}

There appears to be no reasonable doubt that farmer's lung is due to the inhalation of dust from mouldy hay or straw, and it has been recognized by farmers in Devonshire for many years; but, since the exposure is only seasonal, there is not 
the high incidence of ill health amongst farm workers that there is in other industries with a similar risk, and therefore the condition is relatively uncommon.

Mouldy hay or straw has a high "dust" content, which consists of mould spores, together with grass particles, and it is the invariable history in farmer's lung that the farm worker has been breathing air highly charged with hay or straw " dust" before developing the condition.

In an attempt to find out the cause certain investigations have been carried out. Table I shows the result of investigations at five different farms, at each of which there had been a case of farmer's lung, in order to give some idea of the number of mould spores in the air in the farmyard and inside the cowshed, both before and after hay had been shaken up.

TABLE I

RESULTS OF INVESTIGATIONS AT FIVE FARMS

\begin{tabular}{c|c|c|c}
\hline & \multicolumn{3}{|c}{$\begin{array}{c}\text { Mould Content of Air in Cowsheds } \\
\text { (No. of Colonies per Plate) }\end{array}$} \\
\cline { 2 - 4 } Farm No. & $\begin{array}{c}\text { Outside } \\
\text { Air }\end{array}$ & $\begin{array}{c}\text { Air in Cowshed } \\
\text { Undisturbed }\end{array}$ & $\begin{array}{c}\text { After Bringing } \\
\text { in Hay }\end{array}$ \\
\hline 1 & 9 & 78 & 896 \\
2 & 12 & 164 & 1,200 \\
3 & 13 & 125 & 708 \\
4 & 23 & 60 & 1,408 \\
5 & 9 & 237 & 418 \\
\hline Average & 13 & 133 & 926 \\
\hline
\end{tabular}

Petri dishes of malt agar were exposed for five minutes in each case, and it is notable that in the undisturbed air in the cowshed the number of spores was ten times that of the outside air and that after hay had been shaken up the number went up a further seven times. It must also be realized that an average of 926 colonies per plate is such gross overcrowding that it is impossible to get accurate counts, and therefore the true result is a good deal higher.

Penicillia and Cladosporium herbarum were always prominent, but otherwise there was nothing characteristic about the fungus flora.
Sputa from known cases of farmer's lung were cultured for moulds, and the following were grown: Candida albicans, Penicillium (two types), Cladosporium herbarum, and Aspergillus nidulans. There were, however, no constant findings. As a check against these results 95 random samples of sputa sent to the Public Health Laboratory, Exeter, were cultured for moulds, and of these $15.7 \%$ were positive to Candida albicans alone.

Lastly, in an attempt to obtain cultures from the bronchial tree without contamination by the upper respiratory passages, bronchoscopic swabs were taken in four cases. A penicillium was grown in only one case, the others proving negative. A slight inflammatory reaction of the bronchial mucosa was noted.

The one death that occurred in the whole series was of a patient who two years previously had had a well-marked attack of farmer's lung with spontaneous recovery, both clinically and radiologically. On admission to hospital he was so ill that no radiograph could be taken, and he died within 24 hours. Necropsy showed widespread pulmonary tuberculosis with small areas of caseation and many small cavities. Neither culture nor microscopy of the lung tissue showed any evidence of bronchomycosis; M. tuberculosis was, however, present in large numbers.

Investigations have also been carried out to see whether the clinical picture of farmer's lung could be explained on an allergic basis.

Four samples of hay were taken, two mouldy and two good, from farms where cases had $\stackrel{0}{\times}$ occurred. From each of these samples $1 \mathrm{~g}$. of $\frac{0}{3}$ chopped hay was allowed to soak in $25 \mathrm{ml}$. of sterile distilled water overnight at $2^{\circ} \mathrm{C}$. and the $ᄋ$ resulting infusion was put through a Seitz filter. Extracts were also prepared from pure cultures of $\frac{0}{5}$ four moulds obtained from sputa. Each mould $D$ was grown for two to four weeks in a glucose medium similar to that used by Smith (1943) for $N$ the preparation of coccidioidin, and the residual

TABLE II

SKIN TEST RESULTS IN 10 PATIENTS AND ONE CONTROL

\begin{tabular}{|c|c|c|c|c|c|c|c|c|c|c|c|c|}
\hline \multirow{2}{*}{ Extract } & & \multicolumn{10}{|c|}{ Farm-worker Suffering from Farmer's Lung } & \multirow{2}{*}{ Control } \\
\hline & & 1 & 2 & 3 & 4 & 5 & 6 & 7 & 8 & 9 & 10 & \\
\hline 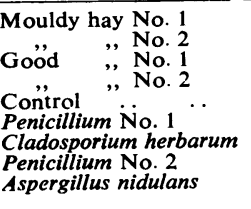 & $\begin{array}{l}\cdots \\
\cdots \\
\cdots \\
\cdots \\
\cdots \\
\cdots \\
\cdots\end{array}$ & $\begin{array}{c}++ \\
++ \\
+ \\
++ \\
- \\
+ \\
+\end{array}$ & $\begin{array}{l}+ \\
++ \\
\overline{+} \\
\overline{-} \\
\overline{+} \\
\overline{t+}\end{array}$ & $\begin{array}{c}++ \\
+ \\
+ \\
++ \\
- \\
- \\
- \\
-\end{array}$ & $\begin{array}{c}\bar{t} \\
+\bar{t}+ \\
\overline{-} \\
\overline{-} \\
++\end{array}$ & $\begin{array}{l}- \\
++ \\
\overline{+} \\
\overline{-} \\
++ \\
\overline{-}\end{array}$ & $\begin{array}{l}++ \\
+++ \\
++ \\
++ \\
- \\
+ \\
-\end{array}$ & $\begin{array}{c}+ \\
+++ \\
+- \\
+++ \\
- \\
= \\
- \\
-\end{array}$ & $\begin{array}{c}+ \\
++ \\
+ \\
++ \\
- \\
- \\
- \\
-\end{array}$ & $\begin{array}{c}+ \\
+++ \\
+++ \\
++ \\
- \\
+ \\
+ \\
+\end{array}$ & $\begin{array}{c}++ \\
++++ \\
+ \\
+++ \\
- \\
= \\
= \\
-\end{array}$ & $\begin{array}{c}++ \\
++ \\
\pm \\
+++ \\
- \\
= \\
= \\
-\end{array}$ \\
\hline
\end{tabular}


fluid from these cultures Seitz-filtered as in the case of the hay extracts.

These eight extracts, together with a control fluid consisting of normal saline, were injected intradermally into 10 patients with farmer's lung and one control (Table II).

It was immediately apparent that extracts of both good and mouldy hay produced a response (flare and wheal) both in patients who had had the disease and in the normal. This response was histamine-like in appearance and similar to that described by Prausnitz (1936) in his investigation of samples of cotton seed.

The extracts from pure cultures of moulds, on the other hand, gave very little response and that so haphazardly as to be of no real value.

\section{Discussion}

There are four possibilities which must be considered as aetiological factors in farmer's lung. First, as held by Fawcitt (1936) and Törnell (1946), we may be dealing with a true bronchomycosis. Fawcitt, in coming to his conclusions, did not appear to realize the prevalence of mould spores in sputum which, when collected in the normal way, is of necessity contaminated by moulds present in the upper respiratory passages.

Men working in an atmosphere such as is described earlier in this paper, and demonstrated by the enormous number of colonies found on the exposed plates, are bound to produce sputum heavily infected with mould spores. The only method of getting over this difficulty is by bronchoscopy, as was done in a few of the cases. Törnell in his investigations found Candida albicans in all his eight cases, but it is important to realize the frequency with which this organism occurs as a saprophyte in the sputum, or actually as a pathogen in the rare instances where the resistance of the patient has been reduced to a low ebb by some debilitating disease. As has been shown earlier, $15.7 \%$ of a random sample of sputa were found to grow Candida albicans, and it is by no means infrequent to find this fungus growing in old tuberculous or bronchiectatic cavities. It is necessary to demonstrate the fungus actually invading the lung before farmer's lung can be accepted as a true bronchomycosis. Short of this, it is only possible to regard the repeated recovery of one species of fungus in sputa or bronchoscopic swabs as being suggestive but far from conclusive.

The second possibility to be considered is that farmer's lung might be due to a bacterial infection. Were this the case it would seem reasonable to expect that microscopy and culture of sputa would reveal some recurrent and constant infecting organism, which has not been so in this series.

A third possibility is that farmer's lung is, in fact, a form of asthmatic response due to sensitization of the patient either to the degradation products of mouldy grass or to moulds themselves. If by asthma one means the bronchial oedema and spasm which occur in sensitive individuals, accompanied by forced expiratory effort and sibilant rhonchi, then farmer's lung is not asthmatic. For in the cases of this series the dyspnoea was not accompanied by forced expiratory effort, the signs in the chest were minimal, and the sputum was scanty and mucopurulent and not of the frothy, sticky, copious quality characteristic of asthma. Furthermore, the radiographic appearances were typical and not in any way comparable either to those of ordinary asthma or the asthma associated with pulmonary eosinophilia described by Crofton, Livingstone, Oswald, and Roberts (1952).

It is not considered that the findings given earlier and summarized in Table II demonstrate anything more than that hay, whether good or mouldy, contains a histamine-like substance, which can produce a " triple skin response."

The fourth possibility is that farmer's lung is the result of irritation of the bronchial epithelium by the breakdown of mould spores and possibly grass particles resulting in miliary inflammatory response. There would appear to be a slow sensitization of the individual over a period of months or years and, furthermore, some peop'e appear to develop this reaction much more easily than others. Thus two men may be working in the same cowshed under the same conditions and one will be affected and the other not. Direct evidence as to the nature of the cellular response is not available; nevertheless it is inflammatory to some extent as is evident from the purulent type of sputum. Zettergren (1950) has carried out animal experiments in which he subjected rabbits to sterile threshing dust and to the same sterile dust mixed with a pure culture of active Candida albicans. Necropsies on these animals showed what he termed submiliary histiocytic lung granulomata (dust granulomata) in the lungs of the animals which were made to breathe the uncontaminated sterile threshing dust. The rabbits which were given threshing dust together with Candida albicans showed a different type of response, which he termed submiliary-miliary tuberculoid granulomata (fungal granulomata). Zettergren stated that the dust granulomata disappear more quickly 
than the fungal granulomata, but found no evidence of multiplication of spores in the rabbit's lung after their inhalation.

Zettergren's work is significant, and it may well be that the changes which occur in the human lung when hay or threshing dust is inhaled are similar to those he found in rabbits. Also it is possible that the property of producing fungal granulomata may be possessed by other mould spores in addition to Candida albicans.

It will be seen that much more detailed work is required on this interesting disease.

The condition itself is not a lethal one, and human histological material is difficult to obtain. It would be most valuable to study the histology of the lung in each of the three phases of the disease if chance opportunities occurred. Another possible line of investigation is the preparation of fractional extracts from the hay and straw known to cause the condition, much on the same lines as those employed by Prausnitz (1936) in his work on chest diseases in operatives in the cotton industry, although the results of Cayton, Furness, and Maitland (1952) in their search for allergens and bacterial antigens in samples of cotton dust were disappointing. A field survey of both affected and non-affected workers on farms where cases have occurred might also yield valuable information.

The present paper leaves many questions unanswered, but is intended to call attention to an occupational disease which has interesting features and which is much commoner in rural areas with a high rainfall than is usually realized and is the cause of a good deal of minor illness amongst farm-workers.

\section{SUMMARY}

Farmer's lung and thresher's lung are synonymous terms. The condition is characterized by a typical radiological and clinical picture.

The condition is due to the inhalation of hay or threshing. dust having an extremely high mould spore content.

Repeated exposure to this dust eventually pro- $\overrightarrow{0}$ duces a response in the bronchial wall which may be of a similar type to that which occurs in rabbits $\vec{\omega}$ and has been described as a fungal granuloma.

The aetiology of farmer's lung is discussed and $x$ a possible line for further study suggested.

My thanks are particularly due to Dr. G. C. i Ainsworth, mycologist at the University College of 은 the South-West, who was responsible for the culture and identification of the moulds from infected sputa and farms in the district ; also to Dr. Brendan Moore, of the Public Health Laboratory Service, who not $\stackrel{\bigcirc}{\Im}$ only prepared the extracts used in skin testing but carried out many of the tests himself. I should also $f$ like to thank Drs. G. Stewart Smith and C. P. Warren $\omega^{-}$ and the technical staff of the Department of Pathology of the Royal Devon and Exeter Hospital for their help, and, lastly, Drs. M. J. Greenberg and G. M. Colson, both medical registrars at the Royal Devon and Exeter Hospital.

REFERENCES

Campbell, J. M. (1932). Brit. med. J., 2, 1143.

Cayton, H. R., Furness, G., and Maitland, H. B. (1952). Brit. J. industr. Med., 9, 186

Crofton, J. W., Livingstone, J. L., Oswald, N. C., and Roberts, A. T. M. (1952). Thorax, 7, 1 .

Duncan, J. T. (1945). Brit. med.'J., 2, 715.

Fawcitt, R. (1936). Brit.J. Radiol., 9, 172, 354

-1938). Ibid., 11, 378.

Prausnitz, C. (1936). Spec. Rep. Ser. med. Res. Coun., Lond., No. 212.

Smith C.E. (1943). Med. Clin. N. Amer., 27, 790.

Törnell, E. (1946). Acta med. scand., 125, 191

Zettergren, L. (1950). Acta Soc. Med. upsalien., 55, 257. 